\title{
Mild Base Mediated Desilylation of Various Phenolic Silyl Ethers
}

\author{
Noel S. Wilson and Brian A. Keay* \\ Department of Chemistry, University of Calgary, Calgary, Alberta, Canada, T2N 1N4
}

\begin{abstract}
A variety of phenolic silyl ethers are easily desilylated in good to excellent yields by treatment with 1.1 equivalents of $\mathrm{K}_{2} \mathrm{CO}_{3}$, and ethanol containing 5 equivalents of water.

Copyright @ 1996 Elsevier Science Ltd
\end{abstract}

Since alcohols are typically very reactive due to their acidity, the alcohol moiety is usually protected for organic synthesis. There are numerous methods available to protect the alcohol moiety. ${ }^{1}$ One protecting group for an alcohol which has gained recent popularity is the $t$-butyldimethylsilyl (TBDMS) moiety. ${ }^{1,2}$ Surprisingly, however, its use as a protecting group for phenols, appears to be less widely accepted. Removal of phenolic silanes with common reagents, such as $n$ - $\mathrm{Bu}_{4} \mathrm{NF} / \mathrm{THF}$, can lead to complex mixtures due to the basicity of the reagents. ${ }^{3}$ In addition, aqueous workups can lead to diminished yields of some phenols due to their high water solubility. Although there is a host of methods known for the desilylation of aliphatic silyl ethers, ${ }^{1}$ to our knowledge, only five methods have been reported for the cleavage of TBDMS phenolic ethers. ${ }^{3-7}$ These include the use of: a) aq. $\mathrm{HF} / \mathrm{NaF} ;^{3}$ b) $48 \% \mathrm{HBr}, t-\mathrm{BuBr}$, $\mathrm{KF} ;{ }^{4}$ c) $37 \% \mathrm{KF}$-basic alumina with ultrasound; ${ }^{5}$ d) neutral alumina in a microwave, ${ }^{6}$ and e) $5 \mathrm{~mol} \%$ $\mathrm{PdCl}_{2}\left(\mathrm{CH}_{3} \mathrm{CN}\right)_{2}$, (wet) acetone. ${ }^{7}$ While each of the above methods has merit, there are some limitations with methods $a-d^{7}$ and method $e$ is limited to nonsterically hindered phenolic silanes and is not selective for the removal of phenolic TBDMS ethers in the presence of aliphatic TBDMS ethers. ${ }^{8}$ We herein report, a new method for the selective removal of a variety of phenolic silyl ethers, which utilizes conventional laboratory reagents and equipment, is performed in a mild basic medium, does not require an aqueous workup, and tolerates a variety of functional groups.

While developing a modified in situ Suzuki cross-coupling of haloarenes for the preparation of $C_{2}$ * symmetric biaryls, ${ }^{9}$ we found that in one example a TBDPS protected $p$-bromophenol was cleaved to the corresponding $p$-bromophenol in excellent yield by treatment with $\mathrm{Na}_{2} \mathrm{CO}_{3}$, and $\mathrm{Pd}\left(\mathrm{PPh}_{3}\right)_{4}$ in a $3: 3: 1$ toluene/ethanol $/ \mathrm{H}_{2} \mathrm{O}$ mixture at reflux. Subsequent experiments indicated the $\mathrm{Pd}(0)$ was not involved in the reaction and that phenolic silyl ethers could be cleaved using $\mathrm{Na}_{2} \mathrm{CO}_{3}$ in ethanol containing 5 equivalents of 
Table 1. Desilylation Results Using A Variety of Conditions with 2-(t-Butyldimethylsilyloxy)Benzaldeyde.

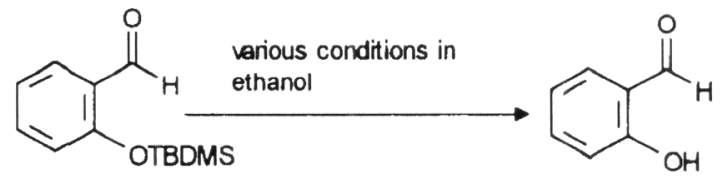

\begin{tabular}{|c|c|c|c|c|c|c|c|}
\hline \hline Entry & Scale & $\begin{array}{c}\text { Amount of } \\
\mathbf{K}_{2} \mathbf{C O}_{3}\end{array}$ & Time (h) & $\begin{array}{c}\text { Temp. } \\
\left({ }^{\circ} \mathbf{C}\right)\end{array}$ & Solvent & $\begin{array}{c}\text { Amount of } \\
\mathbf{H}_{2} \mathbf{O}\end{array}$ & Yield (\%) \\
\hline 1 & $100 \mathrm{mg}$ & 1.1 equiv. & 12 & 75 & ethanol & 5 equiv. & 100 \\
\hline 2 & $100 \mathrm{mg}$ & none & 120 & 75 & ethanol & 5 equiv. & $16^{\circ}$ \\
\hline 3 & $100 \mathrm{mg}$ & 1.1 equiv. & 24 & 75 & ethanol & none & 60 \\
\hline 4 & $1 \mathrm{~g}$ & 1.1 equiv. & 12 & 75 & ethanol & 5 equiv. & 70 \\
\hline
\end{tabular}

a) Isolated yields. b) Heavy decomposition noted.

water. Since a search of the literature indicated that phenolic silyl ethers have not been reported to be cleaved under mildly basic conditions, even though there have been a few reports that aliphatic silyl ethers ${ }^{10-12}$ are removed under basic conditions, we investigated the scope and limitations of this new desilylation method.

We have found that a variety of phenolic TBDMS ethers are easily removed in good to excellent yields by treatment with 1.1 equivalents of $\mathrm{K}_{2} \mathrm{CO}_{3}$ in refluxing ethanol containing 5 equivalents of water (Tables 1 and 2). In the absence of base, a $16 \%$ yield of 2-hydroxybenzaldehyde is obtained after refluxing the mixture for 5 days (entry 2). The reaction takes longer when less water is used and workup is more difficult if more water is used due to the solubility of some phenols in water. The optimized reaction conditions can accommodate themselves to a large scale reaction as illustrated by treatment of 1 gram of 2 ( $t$-butyldimethylsilyloxy)benzaldehyde with 1.1 equivalents of $\mathrm{K}_{2} \mathrm{CO}_{3}$ in refluxing ethanol containing 5 equivalents of water providing a $70 \%$ yield of 2-hydroxybenaldehyde after refluxing the mixture for $10 \mathrm{~h}$ (entry 4). The workup of this reaction is very simple and does not require an aqueous wash phase. After t.l.c. or G.C. indicates that the silyl group has been removed, the mixture is filtered through Celite and the ethanol and small amount of water is removed on a rotoevaporator to leave a residue which is purified by either distillation or recrystalization.

In addition to the removal of the TBDMS ether, the optimized desilylation conditions removed trimethyl- (TMS), triethyl- (TES), tri-i-propyl- (TIPS), and $t$-butyldiphenyl- (TBDPS) silyl phenolic ethers (Table 2, entries 1-5); however, primary, secondary and benzylic silylethers were not cleaved under these conditions (Table 2, entries 6-8, and Scheme 1). Thus, TMS, TES, TBDMS, TIPS, and TBDPS phenolic ethers can be selectively removed in the presence of TBDMS protected aliphatic silylethers. 
Table 2. Results From The Desilylation Of Various Phenolic Silyl Ethers With 1.1 equivalents of $\mathrm{K}_{2} \mathrm{CO}_{3}$.

\begin{tabular}{|c|c|c|c|c|}
\hline Entry & Starting Material & Time (h) & Product & Isolated Yield (\%) \\
\hline $\begin{array}{l}1 \\
2 \\
3 \\
4 \\
5\end{array}$ & $\begin{array}{c}\mathrm{R}=\mathrm{SiMe}_{3} \\
\mathrm{R}=\mathrm{SiEt}_{3} \\
\mathrm{R}=\mathrm{Si}(t-\mathrm{Bu}) \mathrm{Me}_{2} \\
\mathrm{R}=\mathrm{Si}(i-\mathrm{Pr})_{3} \\
\mathrm{R}=\mathrm{Si}(t-\mathrm{Bu}) \mathrm{Ph}_{2}\end{array}$ & $\begin{array}{l}10 \\
10 \\
12 \\
24 \\
48\end{array}$ & & $\begin{array}{c}100 \\
99 \\
98 \\
77 \\
62\end{array}$ \\
\hline 6 & & 24 & & no reaction \\
\hline 7 & & 24 & & no reaction \\
\hline 8 & & 24 & & no reaction \\
\hline 9 & & 16 & & 94 \\
\hline 10 & & 12 & & 100 \\
\hline 11 & & 20 & & 81 \\
\hline 12 & & 24 & & 78 \\
\hline 13 & & 17 & & 96 \\
\hline 14 & & 2 & & 98 \\
\hline
\end{tabular}

a) All reactions were performed in ethanol containing 5 equivalents of water at $75^{\circ} \mathrm{C}$. 


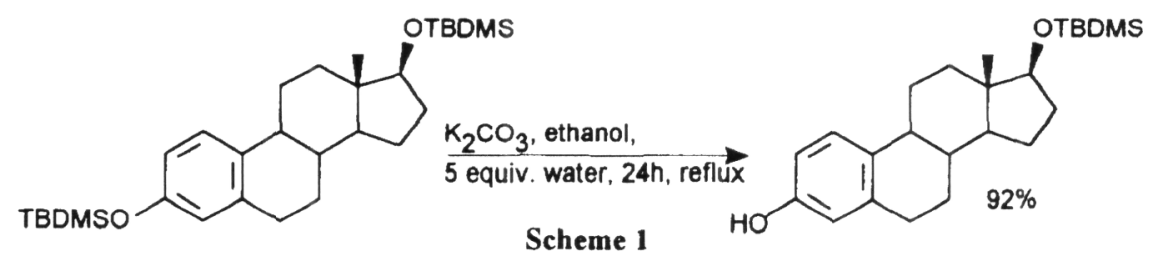

We have developed a simple, inexpensive, selective, mild procedure for the desilylation of phenolic silyl ethers in good to excellent yields, which uses conventional laboratory equipment and reagents, and does not require an aqueous workup.

Typical Experimental: To a mixture of 4-(t-butyldimethylsilyloxy)acetophenone (104 mg, $0.415 \mathrm{mmol}$ ), water $\left(37.5 \mu \mathrm{L}, 2.08 \mathrm{mmol}, 5\right.$ equiv.) and ethanol $(2 \mathrm{~mL})$ was added $\mathrm{K}_{2} \mathrm{CO}_{3}(63 \mathrm{mg}, 0.457 \mathrm{mmol}, 1.1$ equiv.). The mixture was refluxed $\left(75^{\circ} \mathrm{C}\right)$ for 16 hours (followed by t.l.c.), cooled to room temperature, filtered through Celite, and the ethanol and water removed on a rotoevaporator to leave a solid. Recrystallization of the solid from methanol/ethyl acetate solvent mixture provided 4-hydroxyacetophenone in $94 \%$ yield.

Acknowledgments We thank the Natural Sciences and Engineering Research Council of Canada and The University of Calgary for financial support and Neil G. Andersen for his initial desilylation result.

\section{References and Notes}

1. Greene, T.W.; Wuts, P.G.M. Protective Groups in Organic Synthesis, 2 Ed., John Wiley and Sons, Inc., New York, 1991.

2. Corey, E.J.; Venkateswarlu, A. J. Am. Chem. Soc. 1972, 94, 6190.

3. Kendall, P.M.; Johnson, J.V.; Cook, C.E. J. Org. Chem. 1979, 44, 1421.

4. a) Sinhababu, A.K.; Kawase, M.; Borchardt, R.T. Synthesis 1988, 710 . b) Sinhababu, A.K.; Kawase, M.; Borchardt, R.T. Tetrahedron Lett. 1987, 28, 4139.

5. Schmittling, E.A.; Sawyer, J.S. Tetrahedron Lett. 1991, 32, 7207.

6. Varma, R.S.; Lamture, J.B.; Varma, M. Tetrahedron Lett. 1993, 34, 3029.

7. Wilson, N.S.; Keay, B.A. Tetrahedron Lett. 1996, 37, 153.

8. Wilson, N.S.; Keay, B.A. J. Org. Chem. 1996, 61, 2918.

9. a) Maddaford, S.P.; Keay, B.A. J. Org. Chem. 1994, 59, 6501.

10. Malik, A.A.; Cormier, R.J.; Sharts, C.M. Organic Preparations and Procedures Int. 1986, 18, 345.

11. a) Barker, S.A.; Brimacombe, J.S.; Harnden, M.R.; Jarvis, J.A. J. Chem. Soc. 1979, 1499. b) Hanessian S.; Lavallee, P. Can. J. Chem. 1975, 53, 2975. c) Hanessian S.; Lavallee, P. Can. J. Chem. 1977, 55, 562.

12. Hurst, D.T.; McInnes, A.G. Can. J. Chem. 1965, 43, 2004. 